\title{
COTIDIANO ESCOLAR E SARESP
}

BRUNA LAMMOGLIA MARIA APARECIDA VIGGIANI BICUDO

\section{RESUMO}

Com a presente pesquisa, buscamos compreender como o Sistema de Avaliação de Rendimento Escolar do Estado de São Paulo (Saresp) se mostra no cotidiano da realidade escolar. A pesquisa é de caráter qualitativo e efetuada segundo uma abordagem fenomenológica. O Saresp é focado como fenômeno, investigado na expressão da realidade vivida por professores, alunos e demais agentes da instituição escolar. São apresentadas, como resultado da investigação, convergências articuladas pelo movimento de redução fenomenológica que tomou como dados os depoimentos de sujeitos entrevistados e textos teóricos estudados, tendo como eixos: realidade escolar; visão do Saresp; comprometimento com o Saresp; encaminhamentos pedagógicos e políticos com base nos resultados do Saresp; e visão da matemática escolar. 


\section{RESUMEN}

Con el presente estudio intentamos comprender cómo el Sistema de Avaliação do Rendimento Escolar do Estado de São Paulo (Saresp) se muestra en el cotidiano de la realidad escolar. La investigación es de carácter cualitativo y se ha efectuado según un abordaje fenomenológico. Saresp es enfocado como un fenómeno, investigado en la expresión de la realidad vivida por profesores, alumnos y demás agentes de la institución escolar. Como resultado de la investigación se presentan convergencias articuladas por el movimiento de reducción fenomenológica que tomó como datos los testimonios de sujetos entrevistados y textos teóricos estudiados, con los siguientes ejes: realidad escolar; visión de Saresp; compromiso con Saresp; encaminamientos pedagógicos y políticos en base a los resultados de Saresp; $y$ visión de la matemática escolar.

PALABRAS CLAVE SARESP • ABORDAJE FENOMENOLÓGICO • EVALUACIÓN EDUCATIVA • INVESTIGACIÓN CUALITATIVA.

\section{ABSTRACT}

The present study aims to understand how the Sistema de Avaliação do Rendimento Escolar do Estado de São Paulo (Saresp) appears in daily school life. This is a qualitative study, developed to follow a phenomological approach. Saresp is focused as a phenomenon, investigated the expressed reality experienced by the teachers, students and other agents of the school. The results of the study are presented as articulated convergences by the movement of the phenomological reduction, using as the data the testimony of interviewed subjects and theoretical texts. The axes of the present study are: school reality; vision of Saresp; commitment to Saresp; pedagogic and policy referrals based on Saresp results; and, the vision of school mathematics.

KEYWORDS SARESP - PHENOMOLOGICAL APPROACH • EDUCATIONAL EVALUATION • QUALITATIVE RESEARCH. 


\section{INTRODUÇÃO}

Como ponto de partida deste trabalho, efetuamos um estudo sobre o campo da avaliação educacional da perspectiva de sua historicidade. Tomar ciência do desenvolvimento desse tema, das críticas aos modelos trabalhados e respectivos avanços em direção a outros que deem conta das críticas formuladas, constitui um solo firme para a elaboração de análises procedentes e relevantes, bem como de interpretações a respeito de concepções e práticas vigentes na área de educação ou na de avaliação, especificamente. Darmo-nos conta dos significados dos scores provenientes das avaliações efetuadas coloca-nos em posição de decidir a respeito de encaminhamentos possíveis, de modo consequente e comprometido.

1 Ver a respeito: Freitas (2003); Freitas et al. (2009); Soares, Alves e Mari (2003); Soares (2007); Hoffmann (2009); Vianna (2000, 2005); Saul (1994, 2006); Luckesi (1996); MacDonald (1977); Parlett e Hamilton

(1982); Stake (1982); Stufflebeam (2000); Scriven (1967, 1973); Cronbach (2000); Tyler (1974 [1949]); Madaus e Stufflebeam (2000)

Deparamo-nos, neste estudo, com um rol de definições e modos de conceber a avaliação educacional ${ }^{1}$ que se traduzem em diversas práticas e modelos para avaliar os diversos aspectos envolvidos na educação: currículo, aprendizagem, processos de ensino e de aprendizagem, sistemas de ensino, professores, escolas. 
A partir da década de 1990, a avaliação educacional foi impulsionada no Brasil, tendo em vista a inserção do país em um quadro de mudanças globais em relação à política organizacional do Estado. A posição ideológica, denominada neoliberalismo, que sustenta esse movimento contribui para que se teçam embasamentos à efetivação de acordos internacionais, os quais, por sua vez, estabelecem regras e recomendações, inclusive para a área educacional. O quadro apresentado indica que o significado das reformas educacionais delineadas pode ser compreendido da perspectiva do movimento global de que o país participa naquele momento, tendo em vista, inclusive, a reestruturação econômica.

Nessa conjuntura, entendemos que a avaliação pode ser compreendida como política pública, em que se encontram presentes as ideias que alimentam as avaliações nacionais e as internacionais de que o Brasil participa. Essas mudanças e respectivas visões políticas trouxeram alterações estruturais na medida em que incidiram na legislação educacional, cuja carta maior é a Lei de Diretrizes e Bases (LDB), que teve a versão atual assinada em 1996 (BRASIL, 1996).

Além do estudo do campo conceitual em avaliação educacional e sua inserção no cenário internacional, elaboramos um histórico do Sistema de Avaliação de Rendimento Escolar do Estado de São Paulo (Saresp), que trazemos como um dos tópicos deste artigo. Esse solo teórico foi a base que sustentou as análises, feitas seguindo uma abordagem qualitativa fenomenológica das entrevistas realizadas com sujeitos de duas escolas da rede pública de ensino, que apresentamos quando tratamos dos procedimentos da pesquisa. As articulações entre a teoria e as análises das entrevistas são apresentadas como os resultados deste trabalho de investigação, que expõe compreensões ${ }^{2}$ e apresenta considerações acerca do exposto.

Já de imediato, devemos sinalizar que neste estudo não buscamos fazer uma análise da proposta do Saresp ou dos resultados obtidos pelos avaliadores e respectivos significados por eles atribuídos, mas, sim, dirigir o olhar para a realidade vivenciada pelos sujeitos que estão no final da linha das ações hierarquizadas de acordo com o desenho
2 Esclarecemos que "compreender", no âmbito da pesquisa fenomenológica, diz do sentido visado e que se fez para os pesquisadores no movimento da investigação realizada sobre o fenômeno focado, portanto individual, único, situado em um contexto histórico, também único, pois específico. Difere de "explicar", movimento que tem em vista descrever e prever relações entre fatos, acontecimentos etc., enredado na construção de hipóteses e seus desdobramentos consequentes de um ponto de vista lógico. 
dessa avaliação, buscando tomar ciência dos modos como eles vivenciam esse processo e como o compreendem e avaliam. Conforme nosso entendimento, esse olhar atento que nos propusemos a efetuar contribui com o conhecimento já produzido sobre o Saresp.

\section{- SISTEMA DE AVALIAÇÃo DE RENDIMENTO ESCOLAR DO ESTADO DE SÃO PAULO}

O Saresp foi implantando pela Resolução da Secretaria de Educação n. 27, de 29 de março de 1996 (SÃO PAULO, 1996), como uma iniciativa da própria Secretaria. É realizado anualmente, desde então, com exceção de 1999 e 2006, passando por modificações quase todos os anos. Desde o início, o processo de avaliação das escolas de educação básica está vinculado à verificação do cumprimento de determinadas políticas públicas e, ao mesmo tempo, dá sustentação a decisões tomadas acerca de ações futuras. São avaliadas escolas estaduais, obrigatoriamente, e, por adesão, escolas particulares e municipais (com exceção de 2001 e 2002, quando só foram avaliadas escolas estaduais).

Observamos que o Saresp, no seu primeiro ciclo, de 1996 a 1998, se estabelece como um sistema de acompanhamento da progressão dos alunos nas séries cursadas. Em 2001, torna-se uma avaliação para dar sustentação às decisões de encaminhamento do aluno para a continuação dos estudos ou para a recuperação. Em 2002, como não são avaliados todos os alunos, deixa de assumir esse papel. De 2003 a 2005, torna-se uma avaliação censitária para todas as séries e alunos.

O Saresp, a partir de 2007, passa a utilizar a mesma escala de proficiência do Sistema de Avaliação da Educação Básica (Saeb) para que os resultados obtidos possam ser comparados com os do sistema nacional de avaliação. De 2008 em diante, as médias do Saresp têm sido utilizadas para compor o valor do Índice de Desenvolvimento da Educação do Estado de São Paulo (Idesp), tomado como referência para pagamento de bônus aos professores. Nesse mesmo ano, é elaborada uma nova proposta curricular para o estado de São Paulo, que redefine as matrizes de referência para avaliação do Saresp. 
Desde 2008, anual e alternadamente, as áreas de Ciências da Natureza (Ciências, Física, Química e Biologia) e de Ciências Humanas (História, Geografia, Filosofia e Sociologia) fazem parte da prova. Em 2010, ano em que focamos o Saresp na realidade escolar, foram avaliadas as disciplinas Língua Portuguesa/Redação, Matemática e Ciências da Natureza. Foram avaliados os $3^{\text {os }}, 5^{\text {os }}, 7^{\text {os }}$ e $9^{\text {os }}$ anos do ensino fundamental e as $3^{\text {as }}$ séries do ensino médio. O objetivo da avaliação em 2010 foi o de:

[...] fornecer informações consistentes, periódicas e comparáveis sobre a situação da escolaridade básica na rede pública de ensino paulista, assim como, de ser capaz de orientar os gestores do ensino no monitoramento das políticas voltadas para a melhoria da qualidade da Educação Básica do ensino. (SÃO PAULO, 2011, p. 3)

Dentre os instrumentos de coleta de dados para a avaliação estão as provas para os alunos, que avaliam competências, habilidades e conteúdos. O Saresp se apoia basicamente em dados quantitativos, com análises estatísticas e uso de técnicas psicométricas, como a Teoria Clássica dos Testes e a Teoria da Resposta ao Item. São também aplicados questionários de contexto aos alunos e suas famílias, aos professores e à equipe de gestão, com posterior organização e análise dos dados, conforme aspectos descritivos e analíticos, incluindo possíveis associações entre o desempenho dos estudantes e as características levantadas nos questionários.

Esperando-se que as informações sejam lidas e compreendidas por aqueles que estão no cotidiano escolar, são disponibilizados nos relatórios finais: informações pedagógicas sobre acertos de itens; interpretações pedagógicas das escalas de habilidades; sugestões de abordagem dos conteúdos aos professores, que se presentificam principalmente nos relatórios das aplicações mais recentes. São esses os cuidados que a equipe proponente e gerenciadora do Saresp toma, visando ao conhecimento do efetuado e obtido pela diretoria de ensino, escola, seus professores e alunos.

Para além do conhecimento do Saresp, de sua proposta, de seus modos de aplicação e de análise, de seus procedimentos 
de divulgação, tratamos de nos inteirar de trabalhos produzidos sobre esse sistema de avaliação. De modo sistemático, pesquisamos dissertações e teses apresentadas, defendidas e publicadas sobre o tema Saresp, e encontramos quatro teses e 36 dissertações, entre 1998 e 2011.

Com esses resultados, percorremos as pesquisas por ordem cronológica buscando encontrar seus objetivos, metodologia e conclusões. Não foram analisadas as teses e dissertações que utilizaram dados do Saresp apenas para embasar alguma decisão de pesquisa, como qual escola pesquisar, sem uma discussão acerca desse processo de avaliação, ou seja, aquelas que fizeram uso do Saresp como pano de fundo, ou ainda as que somente analisaram aspectos pedagógicos específicos das disciplinas avaliadas, que não Matemática.

Analisamos, então, as pesquisas de Alcantara (2010); Baggio (2005); Bauer (2006); Barbosa (2005); Bosquetti (2002); Carvalho (2008); Cenevive (2006); Chiste (2009); Corrêa (2008); Felipe (1999); Hernandes (2003); Girelli (2009); Kawauchi (2001); Machado (2003); Moraes (2010); Oliveira (1998); Esteves (1998); Rahal (2010); Ribeiro (2001); Ribeiro (2008); Silva (2007); Silva (2006); Teixeira (2005); Vaz (2008); Alves (2011); Lugli (2011); Pinto (2011); Rodrigues (2011); Camba (2011); Túbero (2003); Lopes (2007); Arcas (2009).

Compreendemos que a maioria das pesquisas tratou da análise do impacto do Saresp nas unidades escolares, das concepções dos atores envolvidos e do uso do Saresp como direcionador de políticas públicas.

Dessa forma, destacamos algumas críticas tecidas por essas investigações e que apontam nas seguintes direções: o Saresp não leva em conta o cotidiano escolar e os diversos fatores que influenciam o processo de ensino; os objetivos precisam ser esclarecidos, já que há objetivos não explícitos nos documentos oficiais; a introdução de mecanismos do mundo empresarial na educação; a falta de possibilidade de se analisarem os erros dos alunos nas provas; o estabelecimento de ranking com os resultados da avaliação, o que pode reprimir as escolas; a não articulação entre os resultados da avaliação e o projeto pedagógico da escola; a associação de bonificações aos profissionais da educação aos resultados 
dos alunos; a centralização das decisões acerca do Saresp; a tensão estabelecida entre as lógicas de avaliação formativa e somativa; a dificuldade para que os docentes compreendam papéis e objetivos do Saresp; professores que declaram não haver mudanças em sua prática por causa do Saresp; o treinamento de alunos com simulados e incentivos para que façam as provas; a não utilização de fatores apontados no questionário socioeconômico para compor a avaliação.

Os pontos positivos levantados sinalizam: a potencialidade desse sistema de direcionar ações pedagógicas nas escolas; a mobilização dos profissionais da escola para discutir sobre avaliação e sobre os fatores intervenientes nas dificuldades dos alunos apontadas pelas provas; a disponibilização de uma grande quantidade de informações acerca do sistema de ensino; a possibilidade de accountability, ou seja, a responsabilização ou prestação de contas, principalmente pelas autoridades políticas sobre os serviços educacionais prestados, porém incluindo profissionais da educação e sociedade.

Finalizamos considerando que 12 das pesquisas citadas são documentais, enquanto as demais se baseiam em entrevistas ou observações, sendo que a maioria inclui docentes; e 13 delas são feitas com dados obtidos junto a professores das escolas avaliadas. As que entrevistam ou observam a equipe de gestão, tanto escolar quanto em nível central, são nove. Destacamos esses números para mostrar que são poucas as pesquisas que incluem os alunos nas análises, sendo quatro as que levam em conta entrevistas e observações com os estudantes. As pesquisas tratam de diversos aspectos que podem parecer semelhantes, mas devemos atentar para o fato de o Saresp ter passado por diversas alterações durante os anos, evidenciando ser salutar que seja colocado sob o olhar crítico de estudiosos, contribuindo com a efetivação de uma meta-avaliação desse sistema.

Entendemos que nossa investigação contribui com estudos sobre o Saresp na medida em que foca modos pelos quais alunos, juntamente com os demais sujeitos entrevistados, vivenciam o Saresp no cotidiano escolar, após as mudanças ocorridas nesse sistema de avaliação em 2007. Além disso, em nossa abordagem, destacamos os modos pelos quais o 
Saresp ocorre no cotidiano escolar, não focando diretamente suas consequências, impactos advindos de encaminhamentos, mas, sim, seu modo de ocorrer na realidade escolar, inclusive com diversos apontamentos dos sujeitos em relação a ela, evidenciando o meio onde o Saresp está inserido. Eles revelam a vivência desses sujeitos no cotidiano escolar que, salvo melhor juízo, vai ao encontro das críticas levantadas e que apontam para o fato de o Saresp não levar em conta esse cotidiano. Nossa investigação revela o "como" e ao fazê-lo traz a vida em movimento nas escolas investigadas. Revelou, por exemplo, que os docentes se sentem culpados pelo "fracasso" de seus alunos, vendo-se como os únicos a quem compete zelar pelo ensino visado na avaliação. A compreensão e interpretação que efetuamos dos dados nos permitiu, tendo em vista o todo da análise, tecer ponderações sobre a política da educação, tomada em seu sentido abrangente, da Secretaria do Estado de São Paulo e do país.

\section{PROCEDIMENTOS DE PESQUISA}

Tendo solo teórico o acima mencionado e como norte a interrogação "como o Saresp se presentifica na realidade escolar?", buscamos conhecer essa realidade e a respectiva presença do Saresp indo a escolas em que ele foi aplicado. Presentificar, neste trabalho, traz o sentido do que se torna presente, mostrando-se mediante ações, práticas, atividades, discursos proferidos e outras possibilidades que se materializam nas especificidades dessa realidade.

Por termos decidido efetuar um estudo qualitativo, sem partir de suposições prévias ou de hipóteses a serem confirmadas ou não, e que desse conta dos diferentes aspectos da realidade escolar, entendemos, baseando-nos em estudos a respeito da pesquisa qualitativa (BICUDO, 2011; BORBA; ARAÚJO, 2004; LINCOLN; GUBA, 1985) poder trabalhar com escolas consideradas significativas. Significativa aqui, no âmbito da pesquisa qualitativa fenomenológica, não tem o mesmo significado de significativa na área de estatística, pesquisa na qual deveríamos então buscar escolas que compusessem uma amostra representativa da rede de ensino, podendo, a partir de um 
estudo da amostra, fazer inferências a respeito do todo. A nossa perspectiva diz do destaque de um todo - do solo em que nos movimentamos - em que a pergunta orientadora faz sentido.

O significativo apontou, assim, para as escolas que: atingiram e que não atingiram a meta do Idesp, para que pudessem ser evidenciadas diferenças entre políticas educacionais propostas e atividades na escola, se houvesse; apresentavam mais de um mil alunos matriculados, para que uma gama de depoimentos entre docentes e discentes pudesse ser ouvida, atentando para suas nuanças; participaram da avaliação do Saresp no tempo histórico desse sistema de avaliação, para que suas mudanças pudessem ter sido vivenciadas na escola.

Tendo em vista deixar o investigado se mostrar pelas descrições do vivenciado por aquele que está em situação de vivenciar o buscado (nesse caso a avaliação do Saresp), característica da investigação fenomenológica, a abrangência e profundeza dos relatos evidenciam a realidade em que a experiência vivida ocorre. Essa afirmação é reforçada pela compreensão dos que efetuam análise fenomenológica, de que quando nas descrições as falas começam a se repetir, é momento de se parar com elas, ou seja, de encerrar a obtenção de descrições (MARTINS; BICUDO, 1989).

Com base nessa compreensão, focamos duas escolas (A e B) que atendiam ao buscado. Pode-se perguntar como fica a questão da generalização tão positivamente pretendida pelas ciências naturais e objetivas. Não se buscam, na modalidade da pesquisa efetuada, generalizações de cunho estatístico, mas generalidades do investigado, postas nas sucessivas reduções fenomenológicas efetuadas, ${ }^{3}$ que na pesquisa denominamos, como muitos pesquisadores o fazem, de categorias abertas, pois estão sempre abertas a interpretações possíveis na compreensão da dialética todo-parte-todo. Essas categorias podem ser tomadas como indicadores para pesquisas quantitativas, por exemplo, que busquem dados sobre a totalidade do sistema, ou colocadas como hipótese, no caso de se almejar uma investigação macro.

Nessas escolas entrevistamos sete professores de Matemática; quatro professores coordenadores; duas diretoras; dezoito alunos da $3^{\mathrm{a}}$ série do ensino médio e dezessete alunos
3 Redução fenomenológica não significa simplificação ou um resumo do obtido ou do analisado, porém são articulações sobre articulações de ideias que se enrolam umas nas outras, mostrando sentido e significado cada vez mais abrangentes que englobam as afirmações que se presentificam nessas ideias, evidenciando um sentido mais amplo. 
4 O enxerto hermenêutico é efetuado para que se esclareçam sentidos presentes nas falas dos sujeitos. Abrese uma coluna ao lado da coluna de destaques da descrição obtida por meio do depoimento gravado e transcrito no modo de o sujeito se expressar e se expõem sentidos trazidos pelas palavras ditas, quer se buscando no próprio contexto do depoimento, quer se trazendo possíveis significados dada a polissemia de palavras, quer se explicitando nomes mencionados, ou mesmo significados de expressões populares como "bicho papão", por exemplo. Esses sentidos, assim abertos, contribuem com as unidades de sentido articuladas pelo pesquisador, de modo que fiquem mais claras, sem que se mude o afirmado pelo depoente. São recursos que ajudam o processo de interpretação e de articulações de ideias. do $9^{\circ}$ ano do ensino fundamental. As entrevistas foram realizadas em dezembro de 2010, individualmente com a equipe de gestão e professores, e em grupos de no máximo quatro alunos, garantindo o anonimato da escola e do depoente, e com gravação em vídeo e posterior transcrição das falas.

As transcrições foram analisadas conforme os procedimentos delineados a seguir. Elas foram lidas atentamente pelas pesquisadoras, tantas vezes quanto necessário, para que o sentido do dito nesse discurso lhes fizesse sentido, tendo como norte a pergunta da pesquisa. Esse norte possibilitou serem destacadas as falas que fazem sentido à luz dessa pergunta, denominadas "unidades de sentido" (US), no aludido procedimento. Na etapa seguinte foram elaborados quadros com cinco colunas (como é mostrado no Quadro 1): o número da unidade de sentido; a unidade de sentido destacada; seu respectivo "enxerto hermenêutico", ${ }_{4}^{4}$ que visa a permitir uma análise/interpretação/reflexão de palavras ditas pelo sujeito sob o aspecto do tema investigado; a unidade de significado, que é a unidade de sentido em uma fala articulada pelas pesquisadoras, com compreensões e interpretações permitidas pelo enxerto hermenêutico e articulações desencadeadas no processo de pensamento junto aos autores estudados; e uma coluna organizada com o que diz cada unidade, entendida como invariante no conjunto de falas dos sujeitos. Temos, assim, a análise denominada ideográfica, ou seja, dos individuais (unidades de sentido destacadas no discurso obtido pelas transcrições das entrevistas, individualmente tomadas). Nesse movimento de análise, obtivemos uma grande quantidade de dados, expostos em 851 unidades de significado, reunidas em 469 páginas.

QUADRO 1 - Exemplo de quadro de análise dos dados

\begin{tabular}{|c|c|c|c|c|}
\hline No & $\begin{array}{c}\text { UNIDADE DE } \\
\text { SENTIDO }\end{array}$ & ENXERTO HERMENÊUTICO & $\begin{array}{c}\text { UNIDADE DE } \\
\text { SIGNIFICADO }\end{array}$ & $\begin{array}{c}\text { O QUE FALA A U.S. } \\
\text { (INVARIANTE) }\end{array}$ \\
\hline SP1.2 & $\begin{array}{l}\text { Não sou } \\
\text { efetivo. }\end{array}$ & $\begin{array}{l}\text { Efetivo: Possui cargo concursado } \\
\text { e estável de magistério no } \\
\text { funcionalismo público estadual. }\end{array}$ & $\begin{array}{l}\text { Não é professor } \\
\text { com cargo } \\
\text { efetivo. }\end{array}$ & $\begin{array}{c}\text { Situação } \\
\text { funcional. }\end{array}$ \\
\hline
\end{tabular}

Fonte: Lammoglia (2013).

Por um movimento de reduções sucessivas e mediante diálogo atento norteado pela interrogação que alimentou a 
pesquisa e estabelecido entre pesquisador, autores estudados, documentos oficiais e depoimentos, articulamos cinco categorias abertas, entendidas como características essenciais, ou seja, específicas, do fenômeno investigado, qual seja, a presença do Saresp na realidade escolar. É importante esclarecer o leitor não familiarizado com a pesquisa qualitativa fenomenológica que, nessa modalidade de investigação, não se parte das categorias para então analisar os dados, mas, e nisso está sua peculiaridade, se parte do real vivido, como ele se mostra e nele e com ele buscam-se pelos sentidos do que se evidencia. Esse procedimento está consonante com a máxima husserliana, repetida tantas vezes por Husserl e autores que com ele trabalham, segundo a qual se deve "ir-às-coisas-mesmas" sem partir de pressupostos teóricos que já definam o investigado para explicá-lo, mas focando o que se mostra; e disso que se mostra e no como se mostra, que sempre é perspectival e variado, buscando compreender os invariantes. Essa compreensão é possível pela redução fenomenológica efetuada na pesquisa, apontando para ideias abrangentes que envolvem outras ideias que vêm sendo evidenciadas pelo movimento de análise, e que, ao serem nomeadas, mediante grande esforço dos pesquisadores para encontrar modos de dizer dessa generalidade, constituem as categorias abertas. Portanto, não podemos dizer quais e por que foram essas as categorias que conduziram a análise, mas expor o movimento do pensar compreensivo que é outro, não perguntando por "quais as categorias que sustentam a explicação", mas "a análise do real vivido conduziu a quais categorias abertas e o que essas categorias significam para o fenômeno investigado?".

Assim, a análise do cotidiano escolar, tomando as descrições das entrevistas dos sujeitos investigados, mediante um trabalho de análise hermenêutica entre sentidos e significados do dito, de reduções sucessivas, buscando denominações mais gerais que dessem conta dos sentidos e significados envolvidos em ideias mais gerais, compreendemos que realidade escolar, visão do Saresp, comprometimento com o Saresp, encaminhamentos pedagógicos e políticos efetuados por meio dos resultados do Saresp e visão da matemática escolar nomeavam os muitos sentidos e significados presentes nas falas dos depoentes. 


\section{RESULTADOS OU INTERPRETAÇÃO DAS CATEGORIAS}

ABERTAS

Neste item apresentamos uma síntese de nossa interpretação das categorias abertas, destacando o que elas nos dizem de aspectos essenciais do fenômeno investigado, de acordo com os depoimentos obtidos e o solo teórico no qual caminhamos. As categorias foram articuladas detalhadamente no trabalho de Lammoglia (2013), trazendo ao leitor interessado uma extensa gama de informações a respeito do sistema de ensino público do estado de São Paulo enredadas com depoimentos de seus atores. Neste artigo, devido à grande quantidade de dados analisados, ao restrito número de páginas e à própria característica de um periódico, elaboramos um texto que traz os resultados tratando da essência do fenômeno estudado como um todo, e não com as ricas (porém longas) análises fragmentadas de cada categoria, buscando proporcionar uma visão mais ampla dos resultados do trabalho de pesquisa. Visando a esclarecer o leitor, apresentamos um pequeno resumo do que cada categoria aberta trata.

Realidade Escolar: traz os modos pelos quais a realidade das escolas investigadas é percebida pelos depoentes. Compreender a realidade vivida nas escolas é relevante para os educadores e pesquisadores que efetuam investigações nessa região de inquérito. $\mathrm{O}$ articulado nesta categoria contribui para essa compreensão, na medida em que foram abordados aspectos constituintes dessa complexa realidade.

Visão do Saresp: revela o modo pelo qual o Saresp é visto e tido na realidade escolar em que sua avaliação incide. $O$ tratado nesta categoria abre-nos a horizontes de compreensões e articulações de muitos dos aspectos tratados no trabalho e irradia-se para a interpretação de outras categorias.

Comprometimento com o Saresp: trata do comprometimento dos vários sujeitos envolvidos na avaliação, mostrando-se como um núcleo essencial quando tratamos do assunto Saresp para os atores escolares. A atitude assumida em relação a esse sistema de avaliação concernente ao processo de ensino e aprendizagem e às avaliações feitas na escola é relevante para que certos objetivos da avaliação sejam efetivados ou não. 
Encaminhamentos pedagógicos e políticos efetuados por meio dos resultados do Saresp: as articulações a que procedemos foram tecidas com exposições dos sujeitos acerca de como percebem os encaminhamentos dados aos resultados do Saresp, tanto pedagógico quanto de políticas vindas da Secretaria de Educação, tendo como base os resultados dessa prova e os textos teóricos que tratam da avaliação. À medida que fomos expondo nosso entendimento, também apontamos modificações e atualizações em algumas das políticas citadas. Entendemos que essa categoria se mostra nuclear por tratar do impacto percebido pelos sujeitos entrevistados, tendo em vista os resultados do Saresp.

Visão da matemática escolar: lança luz sobre a visão da matemática que se mostrou para nós à medida que fomos efetuando as análises e as interpretações dos relatos obtidos nos depoimentos acerca das avaliações do Saresp e a da sala de aula, ou seja, aquela avaliação que o professor faz, durante o ano, da aprendizagem do aluno, dando destaque à visão de matemática escolar presente nas falas dos depoentes.

Considerando a totalidade do dito nessas categorias, vemos que nossa pesquisa evidencia a importância do Saresp, visto como um instrumento de avaliação de desempenho de alunos em disciplinas da grade curricular. Mostra-se como um sistema que, ao efetuar essa avaliação, abrange uma complexidade de aspectos intra e extraescolares, como está enunciado em suas proposições. Esta investigação desvela aspectos dessa complexidade estudados da perspectiva daqueles que vivem, no seu cotidiano, a realidade escolar.

O Saresp se mostrou, a nós, por um lado, olhando sua constituição, como um texto consistente em que são explicitadas as habilidades e competências cognitivas avaliadas de maneira clara e fundamentada em teorias apropriadas. Sinaliza as estruturas básicas de conhecimento a serem construídas pelos alunos, expressas em matrizes de referência para avaliação, fundadas em um recorte da proposta curricular. Há uma intenção implícita nesse sistema de avaliação - como está exposto em seus textos de fundamentação, de explanação da prática de aplicação e em relatórios - de sinalizar quais são as estruturas básicas de conhecimento que se 
espera construir pelas atividades de ensino e de aprendizagem trabalhadas pelos professores, descrevendo indicadores ou descritores dessas aprendizagens.

Por outro lado, os depoimentos obtidos junto aos sujeitos significativos revelaram um descompasso entre a proposta como explicitada e implementada em termos de aplicação e de análise de resultados, pela equipe do nível central, e o vivido na realidade das escolas estudadas, ou seja, daquela da equipe regional. Como já era sinalizado por Parlett e Hamilton (1982), no processo de realização da avaliação os manuais e relatórios assumem diferentes formas em uma situação concreta, com objetivos sendo reordenados, excluídos ou esquecidos.

Mesmo constatando, por meio dos depoimentos, que os professores de matemática e membros da equipe de gestão entrevistados apresentam uma formação apropriada à sua posição e firmeza ao declararem fatos da realidade escolar, além de revelarem que são preparados para o Saresp com capacitações da Diretoria de Ensino, evidenciam-se lacunas no entendimento que expressam sobre o proposto nos documentos oficiais. Uma dessas lacunas se refere ao fato de afirmarem não ter acesso ao que é avaliado pelo Saresp, dele tendo conhecimento apenas por alguns exemplos de itens expostos no Relatório Final. Em nosso entendimento, isso pode mostrar desconhecimento da Matriz de Referência de Avaliação (SÃO PAULO, 2009) ou dúvida quanto à correspondência entre a prova e essa Matriz. Destacamos que os itens apresentados nos Relatórios Finais são acompanhados de interpretações pedagógicas acerca das habilidades mobilizadas pelos alunos para responder aos itens de determinado nível de proficiência, baseadas nos resultados gerais do Estado. Não há especificação por escola, o que ocasiona certa dificuldade para que os educadores se apropriem desses resultados, dificuldade essa potencializada pela carência de informações técnicas revelada pelos entrevistados.

Nosso estudo mostrou que há opiniões contrárias no sentido da convergência entre o que é cobrado na prova e o exposto no material referente ao Currículo do Estado. Alguns depoentes afirmam que o solicitado pelo Saresp se aproxima mais do conteúdo do livro didático do que desse material, 
enquanto outros relatam que o Saresp avalia o conteúdo ministrado em sala de aula. Essa divergência de opiniões evidencia pouco conhecimento do material ou da prova, ou até mesmo de ambos, uma vez que o livro didático pode e deve ser usado como complementação do Caderno do Aluno, além de ser fornecido pelo Estado, gratuitamente. Além disso, de acordo com análise feita no Caderno de Professor e do Aluno, o que se diferencia entre os livros didáticos e tal material é apenas o modo como os conteúdos são abordados, destacando-se que um modo de proceder não exclui o outro, mas ambos se intercomplementam.

Lembrando que um processo de avaliação em larga escala incide sobre uma Matriz de Referência para a Avaliação, sendo a última um recorte do Currículo, que é unificado no estado de São Paulo, sugerimos uma análise mais aprofundada das correlações existentes entre a prova do Saresp, o Currículo do Estado de São Paulo e a Matriz de Referência para Avaliação, também levando em conta as diversas discussões na literatura a respeito de como se dão ou deveriam se dar as relações entre o currículo, avaliação e realidade escolar (GIRELLI, 2009; FINI, 2009; ESTEBAN, 2005; ALVES, 2004; LOPES, 2006; SIQUEIRA; DAVID, 2012; JUNQUEIRA, 2009). Entendemos, portanto, que os depoimentos que se encaminham em direção de dizer que a avaliação não converge com o material do Currículo obrigatório merecem ser investigados.

Pelas nossas leituras, vimos que o Saresp foi desenhado para possibilitar interferências no processo educativo enquanto está em curso. Entretanto, pelas convergências obtidas mediante análise dos depoimentos desta pesquisa, há um longo caminho a ser percorrido para que ele se transforme em um instrumento pedagógico em que, na dialética estabelecida entre a análise dos dados trazidos pelo Saresp e o trabalho efetuado na unidade escolar, seja compreendido o ponto de inflexão que indique a direção de mudança no processo educacional. Para tanto, entendemos que a avaliação formativa também poderia ser efetuada pelo poder público, ao buscar interferir no processo educacional com ações como as que dão atenção especial às escolas que 
apresentaram baixo rendimento no Saresp 2010, denominadas "escolas prioritárias".

Sobre os objetivos do Saresp, membros da equipe de educadores das escolas estudadas os entendem de modo muitas vezes divergente daquele exposto nos documentos analisados. Em seus depoimentos, há demonstração de que entendem os objetivos do Saresp como sendo: avaliar os professores e não os alunos; oficialmente verificar a transformação da educação, mas o objetivo real está obscuro; melhorar o ensino e trazer verbas para escola; usar os resultados apenas politicamente; pagar bônus; proporcionar medida em relação ao modo pelo qual o ensino na rede está ocorrendo; controlar o fluxo de alunos por meio do Idesp; verificar como a escola está incorporando os métodos e materiais de uso obrigatório; diagnosticar as dificuldades dos alunos, para nortear o trabalho da escola; punir os professores; descobrir as falhas da escola e redirecionar o planejamento; reprovar ou aprovar alunos; preparar para vestibulares; verificar o que os alunos aprenderam no geral; mostrar o que os professores estão ensinando e a reputação da escola; permitir autoavaliação do aluno; uma desculpa para a aplicação do Questionário de Contexto e investigação da vida do brasileiro; apresentar um feedback sobre o aspecto do ensino no país; obter informações sobre o nível das escolas públicas. Entendemos que isso pode significar que os objetivos do Saresp não fazem sentido na realidade vivida por esses depoentes, ou que eles preenchem lacunas desse conhecimento com o imaginário sobre avaliação.

A realidade das escolas focadas revelou-se, a nós, como complexa e caótica. Os depoimentos indicam que há: muitos alunos por classe; falta de espaço físico adequado para receber e alocar recursos materiais; ausência de possibilidade de atender às demandas das muitas exigências feitas à escola, como, por exemplo, a de trabalhar com deficiências de vários tipos e origens sem profissionais especializados para darem conta das características dessas deficiências, e a de lidar com alunos que apresentam níveis de proficiência muito diferentes em uma mesma classe; falta de professores que permaneçam como responsáveis pela turma durante o 
ano letivo; classes sem professores durante um período razoavelmente extenso do ano letivo. Apontam como um dos aspectos importantes do baixo desempenho de suas escolas nas avaliações externas essa falta de estrutura e de condições de trabalho.

Fortalecendo a explicação desses aspectos, os depoentes apontam também: a falta de valorização do conhecimento como trabalhado na escola e na dimensão do cidadão moralmente educado; a desvalorização do trabalho do professor, da educação e até mesmo do processo avaliativo; a progressão continuada; a falta de comprometimento dos alunos e pais com o processo de ensino e aprendizagem.

Os estudos que efetuamos apontaram para escolas que se mostram sobrecarregadas de deveres a elas atribuídos pela sociedade, e dos quais se veem obrigadas a dar conta, por maiores que sejam os problemas que surjam, criando obstáculos à função de instruir a respeito do conhecimento concernente às disciplinas do currículo e respectivas ações que abrangem modos de estar consigo e com os outros em dimensões pessoais, interpessoais e sociais. Entendemos que, junto a essa sobrecarga, revela-se a ausência de responsabilidade da sociedade, evidenciada por falta de ações dos poderes públicos para dar suporte ao trabalho da escola. Como exemplo, podemos citar a ausência de profissionais especializados, nas duas escolas para auxiliar no desenvolvimento de alunos com necessidades educacionais especiais.

Nosso entendimento, com base na investigação efetuada, aponta na direção de que não há um projeto educacional proclamado e assumido de modo responsável, a médio e longo prazo, que carregue uma política mais abrangente de valorização da educação envolvendo a familiar, aquela veiculada pela mídia, a dos valores expressos pelas práticas de políticos, da Igreja, enfim por essa mesma sociedade. Vemos, diante dessa desvalorização, uma escola lançada ao seu próprio destino, uma Secretaria da Educação se esforçando por preencher lacunas que entende vitais, professores trazendo para si toda a responsabilidade da educação e do ensino que nela está presente, culpando-se por não conseguir cumprir essa tarefa. Ressaltamos que, no sentido da responsabilização, 
assumida como quase única, do docente pela qualidade do ensino, podemos encontrar em Bauer (2012) um estudo sobre as controvérsias existentes na literatura acerca da relação direta entre desempenho dos alunos e avaliação docente, além de uma discussão sobre o uso dos resultados em avaliações estandardizadas para ações de formação docente.

Os alunos depoentes mostram clareza sobre a realidade escolar e a política educacional de que participam, relatando, em diversos grupos entrevistados, a baixa qualidade do ensino que lhes é ofertado, o que, por exemplo, os deixa em desvantagem em processos seletivos, como vestibulares e vestibulinhos. Eles atribuem essa baixa qualidade ao fato de muitos alunos não se interessarem pelos estudos e por haver falta de cobrança em relação ao aprendizado. Essa questão, conforme o explicitado em seus depoimentos, está enredada à prática da política da progressão continuada e à falta de responsabilidade de muitos alunos em relação às atividades escolares. A progressão continuada sofre diversas críticas. Freitas (2009), por exemplo, afirma que, quando da implantação da progressão continuada e dos ciclos, se retirou a avaliação instrucional como poder de aprovar ou reprovar, e não se colocou nada no lugar, nem uma preparação do aluno e professor para a nova situação. Um histórico de sua implantação, reunindo opiniões de diversos especialistas sobre o assunto, pode ser encontrado em Gramari (2008); e esclarecimentos sobre o sistema de ciclos e suas características, em Alavarse (2009).

Nessa realidade evidenciou-se, nas falas dos docentes e da equipe de gestão, um sentimento de culpa quando a escola em que trabalham não atinge a meta esperada, a do Idesp. O fato revela-se como uma culpa solitária, pois se tomam como os únicos responsáveis pelo fracasso do aprendizado dos alunos. Não consideram o todo, a realidade histórico-social que contextualiza seu trabalho. Essa responsabilidade também é expressa na vinculação do bônus ao desempenho dos alunos, conforme depoimentos obtidos e consonantes a trechos de documentos oficiais, que sinalizam que os resultados devem ser utilizados para "monitorar seu trabalho e subsidiar mudanças necessárias para superar um possível 
desempenho insuficiente de seus alunos nos pontos detectados pela avaliação" (SÃO PAULO, 2008, p. 8).

Freitas (2009) argumenta que as políticas públicas têm se preocupado mais com a figura do professor do que com o conjunto dos atores da escola. Entende que não basta o professor se tornar reflexivo para ter melhoria na qualidade de ensino, pois há outros fatores que a impedem, assim como a escola tem outros atores e profissionais. Defende, então, que o conjunto da escola deve ser reflexivo, incluindo os pais dos alunos. Argumenta que a avaliação institucional, aquela feita dentro da própria instituição, pode ser uma mediadora entre avaliações externas e a avaliação do professor em sala de aula. Compreendemos que a existência de uma equipe que realize avaliações internas possa ser uma das ações que contribua para que os resultados do Saresp sejam melhores apropriados pela equipe de cada escola.

Surpreendentemente, dado o contexto em que trabalham e a imposição de uma gama variada e extensa de deveres, a avaliação externa efetuada pelo Saresp evidenciou, em nossos estudos, responsabilidade da equipe educadora, ou seja, daquela formada pelos profissionais que trabalham na escola, atentos ao ensino e aprendizagem dos alunos, bem como a si mesmos e ao andar da escola, ao modo de todos se comportarem no espaço da "con-vivência" entre pares e com os cossujeitos, parceiros da vida vivida em comunidade. Evidenciou que essa equipe caminha em busca de melhorias dos resultados, assumem a accountability permitida por esse sistema. Isso se mostra mediante a disponibilidade para se compreenderem, se autoavaliarem e assumirem os resultados da avaliação; criarem e desenvolverem atividades que se mostram importantes para alavancar o ensino esperando melhorias na aprendizagem, como a implantação de semana de provas bimestrais na escola $B$, fato que apontam como provocador de melhorias em relação à postura dos alunos mediante os processos de ensino e de avaliação.

Compreendemos que accountability, um dos pilares do sistema de avaliação, não deve incidir apenas em uma ponta do fio que interliga o nível central e o regional. Deve, além de gestões pontuais como o bônus, atingir políticas mais 
amplas de intervenção no sistema de ensino, como feedback dos resultados do Saresp, transcendendo o próprio Saresp.

Entendemos que o Saresp é um importante mecanismo para obter informações acerca: da aprendizagem dos alunos nas disciplinas avaliadas; de condições socioeconômicas dos alunos e suas famílias; de fatores que influenciam no modo de ocorrer o processo educativo. Porém, conforme compreendemos, esses dados obtidos e as análises entre eles e o aprendizado ainda não estão sendo trabalhados em suas potencialidades, visando à melhoria da qualidade da educação pública.

Possibilidades para essa avaliação são apontadas pelos próprios depoentes ao se referirem a algumas mudanças que visualizam para o Saresp, dentre as quais citamos: a necessidade de levar em conta o cotidiano escolar e a realidade de cada escola, com o intuito de avaliar o que está sendo feito pelos profissionais que nela trabalham; a existência de um avaliador que vá a cada escola analisar suas condições, ou que essa análise seja feita por membros da Diretoria de Ensino que já conhecem a realidade de cada unidade escolar; a constituição de uma equipe de profissionais que periodicamente fossem até a escola trabalhar os pontos de conflito percebidos e vividos com os professores e equipe gestora. Essas são mudanças visualizadas que revelam a compreensão desses sujeitos de perceberem a ausência de um olhar detalhado para cada escola que permita levar em consideração as diferenças entre elas. Revelam a percepção de que ao serem divulgados os resultados do Saresp, todas as escolas são tomadas a partir de uma mesma "medida" e que os esforços de cada uma, bem como as facticidades do seu cotidiano, não são apontados.

Esse nosso entendimento vai ao encontro do afirmado por Freitas (2003, p. 35), para quem “a escola é um pouco mais complexa do que um conjunto de variáveis a serem manipuladas, e os valores dessas variáveis são de difícil estabilização e transferência para outras situações." Compreendemos que não bastam dados centralizados sobre o desempenho do aluno ou professor; é necessário que esses dados sejam reconhecidos como contextualizados no curso da historicidade da escola, 
tomada em sua individualidade. Portanto novamente aparece a necessidade de que a escola esteja tecnicamente preparada para receber esses dados, e que também se reconheça enquanto instituição.

Um dos encaminhamentos embasados nos resultados do Saresp diz respeito à bonificação por resultados, vinculada ao alcance de metas em relação ao Índice de Desenvolvimento da Educação do Estado de São Paulo (Idesp), consequentemente às notas do Saresp e às taxas de aprovação. Conforme compreendemos, mediante os documentos estudados, o Saresp avalia o desempenho dos alunos em determinadas disciplinas curriculares e o vincula ao bônus dos profissionais da educação, acabando por se transformar, também, em um mecanismo de accountability do trabalho da equipe educadora.

Buscamos compreender o significado do Idesp, criado em 2007, e, pelas nossas análises e interpretações, entendemos que ele promoveu maior divulgação dos resultados das avaliações, pois esse índice sintético permite comparações entre escolas, já que os resultados são dispostos em uma mesma escala. Além disso, tornou-se uma medida que a própria escola procura melhorar, ao buscar cumprir as metas propostas de aumento do índice. Entretanto, esse fato se torna notícias na mídia, que tece suposições, muitas vezes ingênuas, acerca da qualidade do ensino em cada instituição avaliada. Como retroalimentação, essas notícias e ponderações recaem sobre as escolas e seus professores, aumentando seu sentimento de culpa dada a impotência, ainda que, muitas vezes, não consciente, de reverterem o quadro de uma educação que não se mostra de boa qualidade.

Quanto à exposição dos resultados individuais dos alunos, apresentada nos depoimentos como uma reivindicação dos profissionais e alunos, apontamos, devido a estudos e discussões realizados junto ao Centro de Políticas Públicas e Avaliação da Educação (Caed), vinculado à Universidade Federal de Juiz de Fora, que há possibilidade técnica de esses resultados serem disponibilizados, apesar de carregarem um erro de medida que também são individuais, pois dependem do teste que o aluno recebeu e de sua proficiência em determinado assunto. Ponderamos que uma possibilidade para 
disponibilizar os resultados individuais seria divulgá-los mediante uma classificação em níveis, descrevendo o que significa pedagogicamente estar em cada nível. Nesse caso, o erro de classificação seria menor do que o erro individual e proporcionaria aos profissionais da escola e aos próprios alunos o conhecimento de seu desempenho nas provas que realizaram, com possibilidades de desdobramentos.

Um dos tópicos que destacamos refere-se à autonomia da escola, uma vez que no documento de implantação do Saresp está explícito que um de seus objetivos é fortalecer a autonomia para democratizar a gestão. Entretanto, o desenvolvimento do sistema de avaliação a partir de 2007 indica a intenção de tomar os dados obtidos no processo avaliativo para detectar o desempenho de alunos em atividades curriculares presentes na proposta curricular do estado de São Paulo, deliberados externamente, em níveis centralizados de administração. Entendemos, sim, que a administração central deva oferecer nortes, pontos de partida para ações e avaliações do trabalho realizado, seguidas de autoavaliações e mudanças de trajetória indicadas nessas ações. Vemos que a dialética estabelecida entre o trabalho de centralidade dando o norte para uma ação de política pública e a autonomia de instituições do sistema é tênue. A centralidade possibilita também um controle do trabalho da escola pela Secretaria da Educação, criando uma ambiguidade no que concerne ao significado de autonomia que, então, deve ser esclarecido. Essa nossa compreensão é alimentada também pela seguinte afirmação de Camba (2011):

[...] não se pode dizer que essa democracia proferida nos discursos oficiais tenha conseguido se materializar, levando-nos a apontar que a democracia do discurso presente nos documentos oficiais tinha como finalidade dizer que a escola tem autonomia, mas quando são cobrados os resultados e estes são negativos, a escola, os alunos e seus profissionais são levados a assumir a culpa. (CAMBA, 2011, p. 225)

Quanto ao ensino e aprendizagem da matemática, tomamos conhecimento dos resultados obtidos pelos alunos na avaliação do Saresp que se mostraram abaixo do esperado 
e tido como adequado. Nos discursos dos depoentes é afirmado, repetidas vezes, que, embora saibam que essa ciência é importante para a vida do cidadão comum, são de opinião que a matemática é difícil, não gostam de estudá-la e não a compreendem. Esses indicadores, aliados à falta de requisitos básicos dos alunos para cursar determinada série, como saber efetuar uma multiplicação, e à falta de professores para ministrar aulas dessa disciplina durante o ano todo sem interrupção, certamente estão dentre aspectos presentes na complexidade do significado do baixo desempenho obtido nessa disciplina.

Pelas análises que efetuamos, fica evidente que o ensino de matemática, apesar dos esforços para que seja mais significativo, continua sendo um nó na educação básica, na medida em que se enreda com problemas referentes ao modo como está estruturado o currículo, à formação inicial e continuada dos professores, à falta de interesse dos alunos e ao modo cultural de a matemática ser vista por professores e alunos.

\section{CONSIDERAÇÕES FINAIS}

Sendo este trabalho efetuado de modo qualitativo na vertente fenomenológica, não apresentamos generalizações. Explicitamos, porém, generalidades expressas pelas articulações a que procedemos, tendo como dados os depoimentos hermeneuticamente interpretados e a efetivação de reduções, apontando núcleos de ideias e a literatura a respeito de avaliação, também tomada como solo em que os significados de avaliação vão se revelando.

Entendemos que os resultados e procedimentos do processo avaliador devam ser cada vez mais amplamente discutidos e trabalhados, tanto na esfera da unidade escolar como nas esferas da administração pública, tornando-se a avaliação uma atividade democrática, da qual participem atores do processo educacional em um movimento de estudo e reflexão constante do efetuado e do visualizado como importante a ser efetuado. Tomar conhecimento do processo de avaliação é relevante para clareza dos profissionais que trabalham no sistema de educação escolar. Importante, também, é 
divulgar informações à sociedade sobre esse processo, destacando o que significa e que contribuições positivas a avaliação pode trazer para esse sistema.

Nossa pesquisa aponta fortemente a relevância de se realizar, em estudos futuros, uma meta-avaliação do Saresp, como um ponto de inflexão, quando, ao se vislumbrar todo o processo e as respostas recebidas no que concerne à sua realização, se possa pensar sobre o feito e retomá-lo com compreensões mais abrangentes, com indicação de pontos a serem revistos e sinalizações de caminhos a seguir. Essa prática contribui não só para o aperfeiçoamento do próprio sistema de avaliação em larga escala e para políticas públicas de educação, mas também para o avanço em pesquisa sobre avaliação. Desse modo, concordamos com Stufflebeam (2000), que, ainda em 1974, afirma que a meta-avaliação é de interesse da sociedade, para que aceitem ou não conclusões de avaliações e de profissionais da área, a fim de que as avaliações possam ser melhoradas.

Entretanto, em que pese a importância da avaliação, há o perigo de haver uma avalanche delas de maneira que escola $\mathrm{e}$ sociedade fiquem sufocadas e elas se tornem um lugar comum, ou seja, sem significado político e pedagógico. Concordamos com Gatti (2011), que alerta para o fato de que os números resultantes das avaliações estão caindo num vazio. A autora cita, por exemplo, os resultados obtidos pela Teoria da Resposta ao Item traduzidos em números numa escala de proficiência. Segundo ela, são números pouco compreensíveis para os professores, que não informam sobre processos de aprendizagem e desempenhos específicos, cujas informações são genéricas. Ainda de acordo com Gatti, não se discute a validade dos itens para conteúdos de ensino, perdendo-se, portanto, a discussão sobre até que ponto essas avaliações são válidas para as escolas compreenderem o desenvolvimento do aluno.

Tais aspectos foram evidenciados também em nossa pesquisa, portanto apontamos como emergencial que se invistam esforços em capacitar tecnicamente todos os profissionais escolares, com a presença de uma equipe de especialistas em avaliação, que possam eventualmente trabalhar diretamente na escola. 
Entendemos a avaliação de aprendizagem como central ao sistema didático e ao sistema de ensino, o que implica que qualquer mudança que se efetue na avaliação envolve diversas outras mudanças que deveriam ocorrer na organização do sistema de educação como um todo, e vice-versa. Essa compreensão é fortalecida com a afirmação de Perrenoud (1999, p. 144) que diz ser a avaliação formativa apenas "um dos componentes de um dispositivo de individualização dos percursos de formação e de diferenciação das intervenções e dos enquadramentos pedagógicos". Se tais diferenciações forem impossíveis, a avaliação formativa acontecerá apenas no papel.

Ao focar a realidade escolar, a progressão continuada se mostra, nos depoimentos dos sujeitos entrevistados, um grande problema do atual sistema de ensino, devido à falta de estruturas básicas para a sua organização, como é o caso do não funcionamento a contento das atividades de recuperação paralela, nucleares para que a progressão continuada não se transforme em promoção automática. Nessa realidade, a escola se mostrou como um ambiente carente de estruturas básicas para o funcionamento do sistema, de um ambiente acolhedor para que funcione plenamente, de modo que não se transforme em peso para quem a frequenta.

\section{REFERÊNCIAS}

ALAVARSE, O. M. A organização do ensino fundamental em ciclos: algumas questões. Revista Brasileira de Educação, v. 14, n. 40, p. 35-50, jan./abr. 2009.

ALCANTARA, M. S. Políticas de bonificação e indicadores de qualidade: mecanismos de controle nas escolas estaduais paulistas. 2010. Dissertação (Mestrado em Educação) - Pontifícia Universidade Católica de São Paulo, São Paulo. 2010.

ALVES, M. P. C. Currículo e avaliação: uma perspectiva integrada. Porto: Porto, 2004.

ALVES, C. A. C. Táticas docentes frente aos efeitos do Saresp. 2011. Dissertação (Mestrado em Ciências) - Escola de Filosofia, Letras e Ciências Humanas, Universidade Federal de São Paulo, Guarulhos, São Paulo. 2011.

ARCAS, P. H. Implicações da progressão continuada e do Saresp na avaliação escolar: tensões, dilemas e tendências. Tese (Doutorado em Educação) - Faculdade de Educação, Universidade de São Paulo, São Paulo. 2009. 
BAGGIO, S. C. R. Política Educacional, Saresp e discurso de professores: vozes constituídas e constituintes de um sistema e a subjetividade dos professores. 2005. Dissertação (Mestrado em Linguística Aplicada) - Universidade de Taubaté, Taubaté. 2005.

BARBOSA, G. C. A atividade de avaliar no Saresp. 2005. Dissertação (Mestrado em Linguística Aplicada e Estudo de Linguagens) - Pontifícia Universidade Católica de São Paulo, São Paulo. 2005.

BAUER, A. Usos dos resultados do Saresp: o papel da avaliação nas políticas de formação docente. 2006. Dissertação (Mestrado em Educação) - Faculdade de Educação, Universidade de São Paulo, São Paulo. 2006.

. É possível relacionar resultados de avaliação discente com formação continuada de professores? A experiência de São Paulo. Educação em Revista, Belo Horizonte, v. 28, n. 2, p. 61-82, jun. 2012.

BOSQUETTI, M. C. B. Saresp /2000 e a questão da visualização em geometria espacial. 2002. Dissertação (Mestrado em Educação Matemática) - Pontifícia Universidade Católica de São Paulo, São Paulo. 2002.

BICUDO, M. A. V. (Org.). Pesquisa qualitativa segundo a visão fenomenológica. São Paulo: Cortez, 2011.

BORBA, M. C.; ARAUJO, J. L. (Org.) Pesquisa qualitativa em educação matemática. Belo Horizonte: Autêntica, 2004.

BRASIL. Congresso Nacional. Lei n. 9.394, de 20 de dezembro de 1996. Estabelece as diretrizes e bases da educação nacional. Brasília: MEC, 1996.

CAMBA, M. As políticas de avaliação do rendimento escolar e as interfaces na esfera nacional e estadual: análise do Saresp como política de avaliação no Estado de São Paulo, Brasil. 2011. Tese (Doutorado em Educação) - Universidade Estadual de Campinas. 2011.

CARVALHO, L. R. S. Saresp 2005: as vicissitudes da avaliação em uma escola da rede estadual. 2008. Dissertação (Mestrado em Educação) - Faculdade de Educação, Universidade de São Paulo, São Paulo. 2008.

CENEVIVE, R. Democracia, accountability e avaliação: a avaliação de políticas públicas como instrumento de controle democrático. 2006. Dissertação (Mestrado em Administração Pública e Governo) - Fundação Getúlio Vargas, São Paulo. 2006.

CHISTE, M. C. Sistema de Avaliação de Rendimento Escolar do Estado de São Paulo: repercussão do resultado positivo em duas escolas no ano de 2007. 2009. Dissertação (Mestrado Profissional em Ensino de Matemática) - Pontifícia Universidade Católica de São Paulo. 2009.

CORRÊA, L. M. As concepções de professores de matemática de $5^{a}$ série do ensino fundamental sobre sua prática e os resultados do Saresp 2005. 2008. Dissertação (Mestrado em Educação) - Faculdade de Ciências e Tecnologia da Universidade Estadual Paulista, Presidente Prudente. 2008. 
CRONBACH, L. J. Course Improvement through Evaluation. In:

STUFFLEBEAM, D. L; MADAUS, G. F.; KELLAGHAN, T. (Ed.) Evaluation Models: viewpoints on educational and human services evaluation. 2. ed. Boston, EUA: Kluwer Academic Publishers, 2000. p. 235-247.

ESTEBAN, Maria Teresa (Org.). Escola, currículo e avaliação. 2. ed. São Paulo: Cortez, 2005.

ESTEVES, M. E. P. P. Sistema de avaliação de rendimento escolar do estado de São Paulo - Saresp: uma ação planejada. 1998. Dissertação (Mestrado em Educação) - Pontifícia Universidade Católica de São Paulo, São Paulo. 1998.

FELIPE, J. P. Uma análise crítica do Sistema de Avaliação de Rendimento Escolar do Estado de São Paulo. Dissertação (Mestrado em Educação) - Pontifícia Universidade Católica de São Paulo, São Paulo. 1999.

FINI, M. I. Currículo e avaliação: articulação necessária em favor da aprendizagem dos alunos da rede pública de São Paulo. São Paulo em Perspectiva, São Paulo, v. 23, n. 1, p. 57-72, jan./jun. 2009.

FREITAS, L. C. Ciclos, seriação e avaliação: confronto de lógicas. São Paulo: Moderna, 2003. (Cotidiano Escolar).

FREITAS, L. C. et al. Avaliação educacional: caminhando pela contramão. 2. ed. Petrópolis, RJ: Vozes, 2009. (Fronteiras Educacionais).

GATTI, B. Números vazios. Revista Escola Pública, São Paulo, p. 8- 13, set. 2011. Edição Especial: Avaliação Educacional.

GIRELLI, H. Currículo e cultura: elementos do fracasso escolar. Um estudo com base nas provas do Saresp e da Fuvest. 2009. Dissertação (Mestrado em Educação) - Universidade Metodista de São Paulo, São Bernardo do Campo. 2009.

GRAMARI, E. P. S. A implantação do regime de progressão continuada numa escola da rede oficial de ensino da capital e as implicações sobre o cotidiano dos professores: um canal de escuta. 2008. Dissertação (Mestrado em Educação) - Faculdade de Educação, Universidade de São Paulo, São Paulo. 2008.

HERNANDES, E. D. K. Os propósitos e os impactos causados em uma escola na região de Assis pela implantação e pelas mudanças de rumo do Saresp 2001. 2003. Dissertação (Mestrado em Educação) - Universidade Estadual Paulista, Marília. 2003.

HOFFMANN, J. M. L. Avaliação mito \& desafio: uma perspectiva construtivista. 40. ed. Porto Alegre: Mediação, 2009.

JUNQUEIRA, M. O. Relatório de apresentação: Idesp, bônus e acompanhamento das escolas com pior desempenho. Relatório de conclusão do Curso de Formação de Especialista em Políticas Públicas. São Paulo: Fundap, 2009.

KAWAUCHI, M. Saresp e ensino de história: algumas questões. 2001. Dissertação (Mestrado em Educação) - Faculdade de Educação, Universidade de São Paulo, São Paulo. 2001. 
LAMMOGLIA, B. O Sistema de Avaliação de Rendimento Escolar do Estado de São Paulo (Saresp) em escolas da rede estadual de ensino. 2013. Tese (Doutorado em Educação Matemática) - Instituto de Geociências e Ciências Exatas, Universidade Estadual Paulista, Rio Claro. 2013.

LINCOLN, Y. S.; GUBA, E. G. Naturalistic Inquiry. Califórnia: Sage, 1985.

LOPES, A. C. Discursos nas políticas de currículo. Currículo sem Fronteiras, v. 6, n. 2, p. 33-52, jul./dez. 2006.

LOPES, V. V. Cartografia da avaliação educacional no Brasil. 2007. Tese (Doutorado em Educação) - Faculdade de Educação, Universidade de São Paulo, São Paulo. 2007.

LUCKESI, C. C. Avaliação da aprendizagem escolar. 3. ed. São Paulo: Cortez, 1996.

LUGLI, L. C. A análise de dados e a probabilidade nas avaliações externas para o ensino médio: Enem e Saresp. 2011. Dissertação (Mestrado Profissionalizante em Ensino de Ciências e Matemática) - Universidade Cruzeiro do Sul, São Paulo. 2011.

MacDONALD, B. A political classification of evaluation studies. In: HAMILTON, D. et al. (Ed.). Byond the numbers game. London: MacMillan Education Ltd., 1977.

MACHADO, C. Avaliar as escolas estaduais de São Paulo para quê? Uma análise do uso dos resultados do Saresp 2000. 2003. Tese (Doutorado em Educação) - Faculdade de Educação, Universidade de São Paulo. 2003.

MADAUS, G. F.; STUFFLEBEAM, D. L. Program Evaluation: a historical overview. In: STUFFLEBEAM, D. L; MADAUS, G. F.; KELLAGHAN, T. (Ed.) Evaluation models: viewpoints on educational and human services evaluation. 2. ed. Boston, EUA: Kluwer Academic Publishers, 2000. p. 3-18.

MARTINS, J.; BICUDO, M. A. V. A pesquisa qualitativa em psicologia: fundamentos e recursos básicos. São Paulo: Moraes, 1989.

MORAES, C. A. P. Avaliação em matemática na educação básica do estado de São Paulo: pontos de vista dos sujeitos envolvidos. 2010. Dissertação (Mestrado em Educação) - Universidade Metodista de São Paulo, São Bernardo do Campo. 2010.

OLIVEIRA, D. A. F. Uma avaliação política do projeto Saresp. Dissertação (Mestrado em Educação) - Faculdade de Educação, Universidade Estadual de Campinas, Campinas. 1998.

PARLETT, M.; HAMILTON, D. Avaliação Iluminativa: uma nova abordagem no estudo de programas inovadores. In: GOLDENBERG, M. A. A.; SOUZA, C. P. (Org.). Avaliação de programas educacionais: vicissitudes, controvérsias e desafios. São Paulo: EPU, 1982. p. 38-45.

PERRENOUD, P. Não mexa na minha avaliação! Uma abordagem sistêmica da mudança. In: . Avaliação: da excelência à regulação de aprendizagens - entre duas lógicas. Porto Alegre: Artes Médicas, 1999. 
PINTO, M. A. R. Política pública e avaliação: o Saresp e seus impactos na prática profissional docente. 2011. Dissertação (Mestrado em Serviço Social) - Faculdade de Ciências Humanas e Sociais, Universidade Estadual Paulista, Franca, São Paulo. 2011.

RAHAL, S. Públicas de educação: o Saresp no cotidiano escolar. 2010. Dissertação (Mestrado em Educação) - Universidade Cidade de São Paulo, São Paulo. 2010.

RIBEIRO, A. J. Analisando o desempenho de alunos do ensino fundamental em álgebra, com base em dados do Saresp. 2001. Dissertação (Mestrado em Educação Matemática) - Pontifícia Universidade Católica de São Paulo, São Paulo. 2001.

RIBEIRO, D. S. Avaliação do Rendimento Escolar do Estado de São Paulo (SARESP): a educação a serviço do capitalismo. 2008. Dissertação (Mestrado em Educação) - Faculdade de Educação da Universidade Estadual de Campinas, Campinas. 2008.

RODRIGUES, R. F. Usos e repercussões de resultados do Saresp na opinião de professores da rede estadual paulista. Dissertação (Mestrado em Educação) - Pontifícia Universidade Católica de São Paulo, São Paulo. 2011.

SAUL, A. M. A avaliação educacional. In: SOUSA, C. P. et al. (Org.). Avaliação do rendimento escolar. São Paulo: FDE, 1994. p. 61-68. (Idéias, n. 22).

Avaliação emancipatória: desafios à teoria e à prática de avaliação e reformulação de currículo. 7. ed. São Paulo: Cortez, 2006.

SCRIVEN, M. The metodology of evaluation. In: TYLER, R. W.; GAGNÉ, R. M.; SCRIVEN, M. Perspectives of curriculum evaluation. Chicago: Rand McNally \& Company, 1967. p. 39-83, v. 1. (AERA Monograph Series on Curriculum Evaluation).

Goal-Free Evaluation. In: HOUSE, E. R. (Ed.). School evaluation - the politics and process. Berkeley, California: McCutchan, 1973.

SÃO PAULO. Secretária da Educação do Estado. Resolução SE n. 27, 1996. São Paulo, 29 de março de 1996. Dispõe sobre a implantação do Saresp. Disponível em: <http://siau.edunet.sp.gov.br/ItemLise/arquivos/27_1996. htm>. Acesso em: 13 abr. 2010.

Estado, 2008.

Saresp 2007. Sumário Executivo. São Paulo: Imprensa Oficial do

Matrizes de referência para a avaliação Saresp: documento básico. São Paulo, 2009. Coordenação geral, Maria Inês Fini.

Saresp 2010. Relatório Pedagógico Matemática. São Paulo, 2011.

SIQUEIRA, V. A. S.; DAVID, A. São Paulo faz escola: o currículo prescrito e avaliação paulista. In: ENCONTRO ESTADUAL DA ANPAE - SP, 12.; ENCONTRO REGIONAL DA ANPAE SUDESTE, 7., 2012, Campinas. Trabalhos completos... Campinas: Unicamp/FE, 2012.

SILVA, J. C. Conhecimentos estatísticos e os exames oficiais: Saeb, Enem e Saresp. Dissertação (Mestrado Profissional em Ensino de Matemática) - Pontifícia Universidade Católica de São Paulo, São Paulo. 2007. 
SILVA, H. M. G. Gestão educacional e sistemas de avaliação: os pressupostos ideológicos do Saresp e a trajetória das avaliações aplicadas entre 1996 e 2005. 2006. Dissertação (Mestrado em Educação Escolar) - Faculdade de Ciências e Letras, Universidade Estadual Paulista, Araraquara. 2006.

SOARES, J. F. Melhoria do desempenho cognitivo dos alunos do ensino fundamental. Cadernos de Pesquisa, São Paulo, v. 37, n. 130, p. 135-160, jan./abr. 2007.

SOARES, J. F.; ALVES, M. T. G.; MARI, F. A. O. T. Avaliação de escolas de ensino básico. In: FREITAS, L. C. (Org.) Avaliação de escolas e universidades. Campinas: Komedi, 2003. p. 59-92. (Coleção avaliação construindo o campo e a crítica).

STAKE, R. Novos métodos para a avaliação de programas educacionais. In: GOLDENBERG, M. A. A.; SOUZA, C. P. (Org.). Avaliação de programas educacionais: vicissitudes, controvérsias e desafios. São Paulo: EPU, 1982. p. 30-34.

STUFFLEBEAM, D. L. The CIPP model for evaluation. In: STUFFLEBEAM, D. L; MADAUS, G. F.; KELLAGHAN, T. (Ed.). Evaluation models: viewpoints on educational and human services evaluation. 2. ed. Boston, USA: Kluwer Academic, 2000. p. 279 - 317.

TEIXEIRA, M. L. S. A construção de sentidos na avaliação de múltipla escolha do Saresp. 2005. Dissertação (Mestrado em Linguística) - Instituto de Biociências, Letras e Ciências Exatas, Universidade Estadual Paulista, São José do Rio Preto. 2005

TÚBERO, R. O sistema de avaliação de rendimento escolar do estado de São Paulo e os alunos negros das escolas estaduais da região de Piracicaba - SP. 2003. Dissertação (Mestrado em Educação) - Centro de Educação e Ciências Humanas, Universidade Federal de São Carlos, São Carlos. 2003.

TYLER, R. W (1949). Princípios Básicos de Currículo e Ensino. Tradução de Leonel Vallandro. Porto Alegre: Globo, 1974. Título original: Basic Principles of Curriculum and Instruction.

VAZ, R. A. C. Saresp/2005: uma análise de questões de matemática da $7^{\mathrm{a}}$ série do ensino fundamental, sob a ótica dos níveis de mobilização de conhecimentos e dos registros de representação semiótica. 2008. Dissertação (Mestrado Profissionalizante em Educação Matemática) - Pontifícia Universidade Católica de São Paulo, São Paulo. 2008.

VIANNA, H. M. Avaliação educacional: teoria, planejamento e modelos. São Paulo: Ibrasa, 2000.

Fundamentos de um programa de avaliação educacional. Brasília: Liber Livro, 2005. 


\section{BRUNA LAMMOGLIA}

Doutora em Educação Matemática pela Universidade Estadual Paulista “Júlio de Mesquita Filho", campus Rio Claro (Unesp). Professora de Matemática do Ensino Básico Técnico e Tecnológico do Instituto Federal de Educação, Ciência e Tecnologia de São Paulo, campus Salto (IFSP) brunalammoglia@gmail.com

\section{MARIA APARECIDA VIGGIANI BICUDO}

Doutora pela Faculdade de Filosofia, Ciências e Letras de Rio Claro. Livre-docente pela Universidade Estadual Paulista "Júlio de Mesquita Filho", campus Araraquara (Unesp). Professora Titular (aposentada) de Filosofia da Educação da Unesp, campus Rio Claro. Professora voluntária do Programa de Pós-Graduação em Educação Matemática da Unesp, campus Rio Claro. Bolsista produtividade do Conselho Nacional de Desenvolvimento Científico e Tecnológico (CNPq) mariabicudo@gmail.com 